\title{
Age and level of education impact on expectancy and perceived similarity between virtual and real touristic environments
}

\author{
Mariana Magalhães*, Miguel Melo ${ }^{\dagger}$, António Coelho*†, and Maximino Bessa ${ }^{\dagger \ddagger}$ \\ *Depto. de Engenharia Informática, Faculdade de Engenharia da Universidade do Porto, Porto, Portugal \\ $\dagger$ INESC TEC, Porto, Portugal \\ ${ }_{\ddagger}^{\ddagger}$ Universidade de Trás-os-Montes e Alto Douro, Vila Real, Portugal \\ Email: mcmelo@inesctec.pt
}

\begin{abstract}
This paper focuses on the combination of 360-degree video and virtual reality for improving the touristic experience. Three scenarios were considered in this study: two 360-degree video visualizations, each one related to different touristic places, both presented in an immersive way, followed by an actual visit to those places. By comparing these situations, it was intended to determine the degree of perceived similarity between the virtual and the corresponding real sites, and to analyze if the users' expectancy was fulfilled. This research comprised a qualitative analysis using data collection based on questionnaires, which were applied to a sample consisted of 45 participants. The independent variables of the study were the participants' age and level of education. The results show no statistically significant impact between the two independent variables (users' age and level of education) and perceived similarity and users' expectancy. Our findings suggest that virtual tourism can act as an efficient promotion tool, considering that users' perceived destination image is not compromised regarding their age or level of education.
\end{abstract}

Index Terms-Virtual Tourism, 360-degree video, User's Expectancy, Perceived similarity

\section{INTRODUCTION}

The increasing popularity and accessibility of the virtual reality technologies associated with the urge to make a more consumer-oriented communication in the tourism sector are emerging new ways of presenting touristic information, by including the user in a virtual environment where one can discover and experience new places. As discussed by [1], virtual reality has a vital role in tourism marketing and management, since it can act as a "try before you buy" experience, and its ability to give the users the sense of what it is like to be there. The 360-degree video, a typical format used on virtual reality, in which the spectator is centered in a single position for the visualization of a sphere or near-sphere video, entails numerous opportunities and challenges [2].

In the case of virtual tourism, virtual reality and 360-degree video can be a way of promoting touristic destinations, once its all-the-way-around effect that allows the user to be in a complete 360-degree panorama and view any angle he wants to [3]. It provides multi-sensory information, such as visual, auditory and kinaesthetic, which contributes to users' immer-

978-1-7281-6378-9/19/\$31.00 @2019 IEEE sion [4]-[6] and to the users' perceived realistic representation of the environment [7].

Tourism is an intangible sector, which means that consumers need to sacrifice a tangible good (money) for only expectations [8]. For that reason, the acquisition of a touristic product or service is often associated with consumers' apprehension due to the uncertainty of visiting a place they have never visited before [8], [9]. To avoid the inherent risks and uncertainties in the purchase of tourism products or services, consumers seek information in a large variety of sources [10], which contribute to form their previous image of the destination (users' expectations) [11]. For quite some time, touristic information came from books, articles, reading advertising or it was based on the information exchange with friends and family [12]. Verbal elements dominated marketing communication due to the primary or nonexistent technological resources. Nowadays Internet, and particularly media websites, are used to search for touristic information, helping consumers making better decisions [13], [14]. By all this kind of information, users can form more firmly their own expectations, and easily evaluate a product or a service before purchasing it or before using it, consequently [15]. More than the verbal elements representing the information, visual elements constitute an important factor in a successful promotion campaign of a certain destination [16]. They can act as "mental short-cuts" for information processing in the decision-making process [17] since their contribution to the memorability of the individuals [18]. The presence of visual elements in tourism promotion helps on the consumers' mental perception of the destination (destination image) [19]-[21] before traveling. Destination image can be described as the whole impressions about a destination, including knowledge and feelings [19]. The similarity between consumers' mental representation of the destination and the actual place is an important factor that leads to tourists' satisfaction and that encourages them to recommend that destination to non-visitors, as their friends and family, as mentioned by numerous authors [8], [19], [22]-[24]. In fact, destination mental representation assists consumers to anticipate their tourism experiences [25]. Therefore, there must be intensive, active and dynamic consumer-oriented communication, to optimize consumers' mental representation of the 
destination, to improve their expectations and to, consequently, ensure their satisfaction [11], [23], [24].

This paper aims at studying the use of virtual reality technologies as a tool for tourism promotion. For that, the paper focuses on the combination of 360-degree video and virtual reality immersive technologies for improving the touristic experience, where virtual scenarios are compared with the real scenario using virtual reality immersive technologies. Participants' expectancy and perceived similarity are evaluated, taking into consideration demographic factors (age and level of education).

\section{LITERATURE REVIEW}

\section{A. Demographic characteristics impact on users' virtual ex- perience}

Several studies provide evidence that tourists' mental perception of the destination plays a great role in consumers' behavior, highlighting to decision-making process [19], [20], [26] and to consumers' satisfaction [23], [26], [27]. A preconceived image of a place tends to generate a positive effect on the consumers' beliefs of a future tourism experience [23]. Since a destination with a strong and positive image is more likely considered and chosen [28]-[30]. [28] considers the destination image as one of the most influencing factors for the decision-making process. Besides that, [31] believes that the success of the tourism industry is largely dependent on the tourists' destination image. Also, [29] defend the crucial impact of tourists' destination perceived image for the success of marketing positioning strategies in the international arena, specifically in the developing countries. All these ideas support Phelps' belief [32], who, in 1986, argued that tourism marketing must invest and optimize tourists' perceived image of the destination, to encourage and persuade more people to visit certain places.

As determined by some authors [19], [33]-[35], destination image can be influenced by some socio-demographic characteristics, such as gender, age, level of education and race. Age and gender are usually pointed as the main individual characteristics that can influence users' perception of the virtual environment, in particular in their sense of presence [36][40]. However, some earlier studies revealed that gender has no significant impact on the virtual experience, regarding: users' perception of the virtual environment in the accomplishment of some virtual tasks [41]; concerning users' sense of presence (in this case, tested on middle school students) [42], and users' perception of spatial presence [43]; considering exposure time for users' sense of presence [44]; as well as regarding users' navigation performance in virtual environments [45] and users rotational and translational movements [46]. These are the main reasons why gender was disregarded for this study. Concerning age, [29] suggests a significant relationship between different age groups and consumers' perception of products, services and destination images. Despite all the studies made so far, the uncertainty of the interference of the level of education on the users' virtual experience remains the reason why we included it in this study.

\section{B. Destination mental representation}

Since tourism is an intangible area, the image of touristic products is different from the traditional tangible ones [26], since there is not a "try before you buy" experience [1]. Destination image can be described as a sum of individuals' beliefs, ideas and impressions of a destination [47], which contribute to the consumer's mental representation of the place [23]. It is also defined as an individual representation of the overall impression of the destination [20], resultant of perceptual and affective evaluations of that place [19] or, according to [20] resultant of psychological (abstract characteristics) and functional characteristics. Although it is easier to build a destination image after visiting it, what [32] defines as "primary image", it is also possible to construct a mental representation of a destination even if never visited it before, since it can be formed from several sources of information, such as magazines, celebrities (opinion leaders), television and Internet [10], [18], [48], [49].

Several studies have revealed the technological influence on the relationship between the user and the virtual environment, which can affect how one perceives the virtual experience. Contrarily, human factors are significantly less explored [40], [50]. As determined by some other authors [36], [38], [40], [51], media form and content might result in different virtual experiences, since there is a different sense of presence degree for the users, according to their characteristics, even when facing the same experimental task [52]. [52] suggests that this is one of the main reasons why the role of individual characteristics for the study of virtual experiences cannot be ignored. Also, [53] considers the idea of "one size fits all" is not suitable concerning virtual environments, agreeing with the notion that it must be explored according to the users' individual differences. Individual differences include physiological, psychological and socio-cultural this one also addressed as "demographic characteristics" [40].

\section{Tourist's expectations}

Tourists' satisfaction is largely dependent on their expectations about the destination before experience the reality of the place [12], [23], [54]. In other words, the anticipation of a product (or in the tourism case, a service) through a mental representation of the destination is the basis of consumers' expectations [11]. Indeed, consumers' satisfaction is not only but also determined by the comparison of their evaluation of the product/service and their actual performance, which can be similar or different, respectively, when expectations are confirmed or disconfirmed [54]. The match or the mismatch of the consumers' mental representation with the actual destination determines the confirmation or disconfirmation of the users' expectations [12], which can result in a positive or in a negative consumer experience, respectively [55]. In the marketing literature, this idea refers to "service quality", which is based on the "disconfirmation theory" that states that the consumers' satisfaction with a service is dependent on the meeting or on the exceeding of their expectations with that service [56], [57]. In the case that consumers perceive 
a discrepancy between their prior beliefs and its actual performance, a psychological conflict is generated [54]. Negative expectations can persuade the consumer to take a different decision from the initial, for instance, not to travel to that destination. Moreover, the discrepancy between users' perceived image of the destination and the perceived reality after the travel can dissuade the tourists' intentions to revisit that place [12]. On the contrary, when consumers' expectations match the reality, a positive action is generated, such as a tendency to reinforce consumers' loyalty to the travel agency [11], [23]. As determined by [11], the perceived image of a travel agency is the most important factor in the generation of consumers' expectations. Consumers recognize a set of capabilities and skills in the travel agency, which generates a higher level of confidence in it. Thereby, the authors postulate the following sequence "expectations $\rightarrow$ satisfaction $\rightarrow$ loyalty", in which is highlighted the fundamental role of the travel agency.

Based on the users' expectancy match/mismatch, a comparison between users' experience in a virtual environment and the experience in the actual place was intended to explore. For this research, consumers' expectations are used according to Oliver's definition [54], who defines expectancy as the individual's beliefs about the future performance of a product. More specifically, the expectancy construct is underpinned by the participants' beliefs about the destination after visualizing a 360-degree video promoting it.

\section{Methodology}

This investigation undertook a within-subjects experimental study with a quantitative focus. It aimed to explore users' expectancy after visualizing a 360-degree video in an immersive environment about a touristic destination, as well as their perception of similarity between the virtual and the real place. Participants had the opportunity of visiting both virtually (using a head-mounted display HMD) and physically two Portuguese places. Participants' age and level of education were the independent variables considered for this investigation; perceived similarity and expectancy were the dependent variables.

\section{A. Sample}

In this study, we used a convenience sampling based on a non-probabilistic method, consisted of 45 volunteer participants (21 male and 24 female) between 18 and 79 years of age $(M=42.27$, S.D. $=17.567)$. The participants were divided into two groups: the first group $(N=22)$ has visualized the São Leonardo da Galafura video and the second group $(N$ $=23$ ) has visualized the Capela Nova video. All participants reported normal or corrected-to-normal vision. All participants concluded the experiment.

\section{B. Materials}

For this first experiment, participants were exposed for a maximum of 2 minutes to each 360-degree video, considering that the exposure time is not correlated with users' sense of presence [44]. The videos were captured by the research team using ere captured by making use of a 360-degree 3D mount for goPro cameras using 12 goPros that captured both image and sound of the real locations. After the capture, the videos were processed to merge the multiple footage. A post-production was also performed to ensure that there were no artifacts such as stitching or color problems. The final video had a top/bottom layout with a resolution of $4000 \mathrm{x}$ 4000 (top/bottom layout). The immersive environment was delivered using Oculus Rift Development Kit 2 (DK2) and a headset (Audio-Technica M40x), in a quiet and noiseless space. The stimuli presented in the videos consisted of the virtual transportation of the participants to the viewpoint of So Leonardo da Galafura.

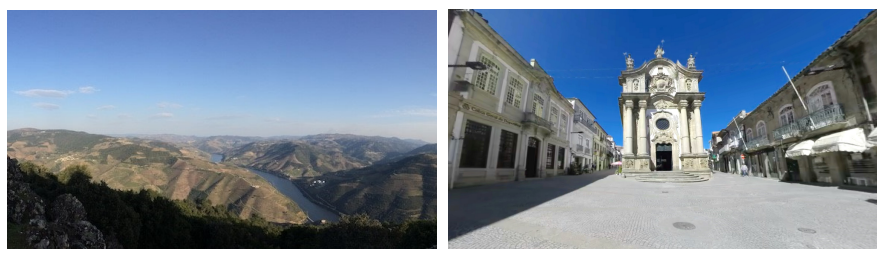

Fig. 1. Screenshot of São Leonardo da Galafura (left) and Capela Nova (right) - illustrative frames of the videos.

\section{Study Variables}

The independent variables of the study are the participant's age and the participant's level of education. The age groups were consisted of "low-age group" (participants between the age of 18 and 48 years old) and "high-age group" (participants over 49 years old). The scholar level group was consisted of "low-education group" (participants with no superior education "without qualifications"; "basic education"; "high school"; "intermediate course") and "high-education group" (participants who were attending or who concluded any university course "bachelor's degree"; "master's degree" and "PhD").

The dependent variables of the study are the participant's expectations and the perceived similarity between the virtual and the real environment.

The experiment was performed in two places instead of a single one, to ensure that the participants would feel some affinity with at least one of the places and, therefore, to avoid biased results. In fact, emotions are one of the multiple factors that play an important role in consumers' satisfaction in tourism [23], [55], occurring "as a result of the cognitive appraisals of experience", since the consumers' enjoyment is based on their own experiences [23]).

It was sought to find attractive touristic places for the experiment, but also unknown for the participants, in order not to interfere with the perceived similarity and expectancy results. There was a great concern to perform the physical visits in the same weekday and at the same time of the original video capture, to accurately ensure that the visual and audio elements presented on the scenario of the virtual visit corresponded to the actual ones. Thus, in the virtual 
experiment, it would be possible to transmit an identical sensation of being in the real place.

According to participants' age and level of education, randomly half of them (22 participants) visualized the 360degree video about the viewpoint of São Leonardo da Galafura (labeled as "Place 1") and then visited the actual place; the other half (23 participants) visualized the 360-degree video about the Capela Nova (labeled as "Place 2") and then visited the actual place. Fig. 2 illustrates the described experiment.

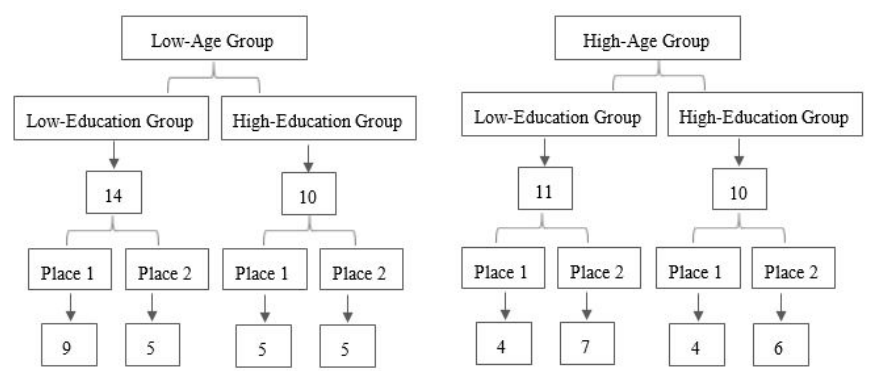

Fig. 2. Participants' segmentation according to their age and level of education.

\section{Instruments}

The dependent variables of this study are "perceived similarity" and "expectancy". As mentioned before, according to some authors [8], [19], [22], [24], the perceived similarity between consumers' mental representation and the actual place is an important factor that leads to tourists' satisfaction. By measuring users perceived similarity, it was intended to find out if there is a great visual discrepancy between the users' mental representation of the virtual environment and the actual places. Besides, it was intended to explore if the immersive video had created an adequate mental representation of the actual place, and if the users' expectations were fulfilled.

To achieve these results, we needed to develop an entire new questionnaire, since no existent method allows us reaching these purposes. The questionnaire encompasses six questions to explore the perceived similarity construct and six questions to explore the expectancy construct. The twelve included questions were translated from the originals (wrote in Portuguese).

The construction of the questionnaire took into account the use of a simplified and clear discourse, with no ambiguous expressions, and the use of an accessible vocabulary, as suggested by [58]. A 5-point Likert-scale from "Strongly disagree" to "Strongly agree" was provided for the responses. A pilot study with five participants was firstly conducted, to check the actual performance of the questionnaire, and to gather some feedback concerning wording, clarity and ambiguity of the expressions [58]. All the construction was followed by one bilingual expert and one $\mathrm{PhD}$ in psychology with an expertise in psychometrics to ensure the proper translation of the questions and that they were asking what was intended to be measured.

The six items that evaluate the participants' perceived similarity between virtual and real place:
- "I feel like I have already been here before."

- "I feel like I saw nothing new."

- "This place looks familiar to me."

- "I saw some things I had not seen in the virtual experience."

- "I did not observe any differences comparing this landscape with the virtual one."

- "The virtual experience would have been enough to know this place."

For assessing participants' expectancy, it was defined the following items:

- "The feeling I had being physically in this place was greater than during the virtual experience."

- "I felt I had a good spatial perception of the place during the virtual experience."

- "I felt an affinity with this place." / "I enjoyed this place."

- "I think it is more pleasant to be physically in this place than just experience it virtually."

- "If I had not come to this place, I would feel the same."

- "I believe that the virtual experience prompted me to visit this place."

\section{E. Procedures}

The experiment was divided into two stages: the first one was the virtual experiences and the second one was the physical visit to the places. Virtual experiences were performed with a maximum of 2 participants at a time, which occurred according to the following procedure:

1) Explanation of the experiment, general instructions and clarification of doubts;

2) The participants have read and authorized the experiment by signing up "Free, prior and Informed Consent", in which was explicit the participants' rights to abandon the experiment at any time they want;

3) Filling the socio-demographic questionnaire, in which were included the participants' age and level of education (independent variables);

4) Test the fit of the equipment;

5) Visualization of the first 360-degree video (Place 1) using virtual reality equipment;

6) Visualization of the second 360-degree video (Place 2) using virtual reality equipment;

7) Physical visit to the Place 1;

8) Answering the questionnaire regarding the comparison between the virtual experiment of the Place 1 and the actual visit to that place;

9) Physical visit to the Place 2;

10) Answering the questionnaire regarding the comparison between the virtual experiment of the Place 2 and the actual visit to that place.

In the first stage, particularly in the fifth and in the sixth steps according to the described experimental procedure, participants were free to observe the places by moving their head and exploring in 6 degrees of freedom (6DOF), with a 360degree overview. Secondly, participants were free to physically 
examine the actual place (seventh and eighth steps according to the described experimental procedure).

From point 1 to 6 (inclusive), every step was performed in the same moment with each participant, limited to 15 minutes at most. 360-degree videos visualization lasted a maximum of 2 minutes. The minimum duration was dependent on the participants, who could quit whenever they want.

\section{F. Statistical Procedures}

The first step was to verify if the collected data was normally distributed. The normal distribution was verified through Skewness and Kurtosis values that, according to [59] must range between $p m 2$ to be considered normally distributed. To proceed to the analysis of the independent variables, age and level of education, it was first verified if there were significant differences between the two videos used in the study to understand if they could be grouped for the statistical analysis or if they should be analyzed independently. For this, the homogeneity of the variances was assessed using a Levene's test and the comparisons were made performing an independent-sample t-test. As there were no differences between the videos, and bearing into mind that the study considers two independent variables (age and level of education) on two dependent variables (expectancy and perceived similarity), we analyzed the data performing a twoway MANOVA test (a Box's $M$ test was used to verify the homogeneity of covariance matrices). Due to a medium the effect size and considerable observed power, one performed univariate tests to verify the potential existence of a type II error.

\section{RESUlts}

A preliminary analysis to verify the normal distribution of the data was conducted, having as reference the Skewness and Kurtosis values. Skewness values were between -0.732 and 0.810 and Kurtosis values ranged from -0.532 to 0.918 , which indicated a normal distribution of the data.

The first step was to verify if there were statistically significant differences between the two videos used. Levene's test for equality of variances assessed that there was homogeneity of variances for both expectancy and perceived similarity ( $p=0.815$ and $p=0.197$, respectively). Regarding expectancy, there were no statistically significant differences between São Leonardo da Galafura (3.841 \pm 0.478$)$ and Capela Nova (3.979 0.447), -0.139 (95\% CI, -0.417 to 0.139 ) $t(43)=-1.006, p=0.320$. The same was verified for perceived similarity there were no statistically significant differences between São Leonardo da Galafura (3.432 \pm 0.664$)$ and Capela Nova $(3.268 \pm 0.825), 0.161$ (95\% CI, -0.287 to 0.616$)$ $t(43)=0.734$.

As there were no differences between videos for both expectancy and perceived similarity, we performed a twoway MANOVA test. To verify the assumption of the twoway MANOVA regarding equal variances and covariances the matrices, we applied a Box's M Test of Equality of Covariance Matrices. The Box's M test revealed that there was homogeneity of covariance matrices $(p=0.721)$. The two-way MANOVA analysis suggests that the interaction effect between age and level of education was not statistically significant, $F(2$, $40)=2.229, p=0.113$, Wilks' $\lambda=.897, \eta_{p}^{2}=.103$, O.P. $=$ 0.440 . However, as it was observed a medium effect $(<0.06)$ and a considerable observed power $(>0.40)$, we performed an univariate analysis to verify the possible existence of a type II error.

The univariate analysis revealed that there was no interaction effect between age and level of education for both expectancy $\left(F(1,41)=3.774, p=0.059, \eta_{p}^{2}=0,084\right.$, O.P. $=0.475)$ and perceived similarity $(F(1,41)=0.033, p=$ $0.857, \eta_{p}^{2}=0.001$, OP $\left.=0.054\right)$. Again, due to a moderate effect $(>0.06)$ and considerable observed power $(>0.40)$ regarding expectancy, we performed univariate tests regarding this dependent variable at every levels of the independent variables age and level of education. The univariate tests for the independent variable age revealed no statistically significant differences between the two groups, $F(1,41)=0.140, p$ $=0.710, \eta_{p}^{2}=0.003, O . P .=0.065$. The univariate tests for the independent variable level of education also revealed no statistically significant differences between the two groups, $F(1,41)=0.351, p=0.557, \eta_{p}^{2}=0.008, O . P .=0.089$.

\section{Discussion}

Results from this investigation showed that there are no statistically significant differences between the studied variables. Such results suggest that virtual tourism can act as an efficient promotion tool, since it does not affect the image of touristic places, independently on users' age and level of education. In other words, our results indicate that these demographic characteristics might not compromise users' perceived destination image. Thereby our study corroborated the literature that argues that individuals with different demographic characteristics might have, at least, a similar mental representation about a certain place after virtually visiting it, considering that destination image can be defined as an individual representation of the overall impressions of the destination [19], [20], [47].

Since in the first stages, purchasing a tourism product/service is all about purchasing expectations [8], and considering that satisfaction/dissatisfaction is the result of that [23], [24], it is essential to understand that expectations and satisfaction must be balanced. This equilibrium ensures that consumers will not get frustrated and contributes to increasing their loyalty and confidence in the travel agency, taking into mind the sequence "expectations $\rightarrow$ satisfaction $\rightarrow$ loyalty", assessed by [11]. The guarantee that consumers will meet their expectations and, consequently, will be satisfied after a virtual tourism experience can be achieved if consumers realize that their mental representation of the destination is similar to the actual place [8], [19], [22]-[24]. This conclusion reinforces the vital relationship between perceived similarity and expectations when comparing virtual places with the actual ones. Hence, we highly suggest that future research with 
a focus on the comparison between virtual and real places, also consider both factors.

\section{CONCLUSions}

Our findings indicate that neither for expectancy nor perceived similarity, the effect of age and level of education was statistically significant. As mentioned before, this indicates that these demographic characteristics might not compromise users' perceived destination image, which emphasizes the value of virtual tourism as an efficient promotion tool.

The capture of the immersive content used in this paper involved a complex apparatus, as, at the time of the capture, there were no technologic options to simplify the process. However, the technological evolution has already put forward devices that at a consumer-cost range that allow a straightforward capture of 360-degree content and allow anyone to capture 360-degree videos easily. Also, given the constant development of the ICT and the permanent innovation in the tourism sector, we believe that shortly the use of immersive features to promote tourism will be more usual, by providing virtual reality equipment to the consumers in the travel agencies, for instance. This method could handle the typical consumers' hesitation at the moment of decisionmaking, providing a better representation of the destination, as mentioned by many authors [19]-[21] than the traditional ones. Furthermore, the digital promotion also addresses some environmental issues, contributing to reduce paper consumption in travel agencies, which is pointed out by some authors as a common way to present information [10], [18], [48], [49].

Based on our experience during this investigation, and considering future investigations focusing the same field of study, there is a particular advice we would like to highlight, which is related to the selection of places: even though both experiments were tested in outdoor areas, the viewpoint of São Leonardo da Galafura is a broader and more recondite space, where persons were spatially dispersed and where they could quietly explore and experience the landscape, mainly surrounded by nature. In turn, Capela Nova is located in a small square in the historic center of Vila Real, a frequent crossing point for many people, that is surrounded by many stores, and where there is a high flow of people in a less ample space when compared with the viewpoint of São Leonardo da Galafura. Thereby, in Capela Nova participants were physically closer, which propitiates more contact between them, for instance, a conversation, which can distract them from the main purpose. Concerning this, and taking into account that the influence of human factors is significantly less investigated than the technological ones [40], [50], we suggest that similar future investigations consider higher affinity between the studied places.

We hope that this investigation encourages some other researchers to explore the influence of human factors on the users' perceived virtual experiences, taking into consideration both perceived similarity and expectancy constructs, as mentioned before. We believe that this type of information contributes to the innovation of the tourism sector, particularly in planning and management in marketing strategies, by understanding the role of individual characteristics for the users' perceived experience in virtual environments.

\section{ACKNOWLEDGEMENTS}

This work was partially financed by the ERDF European Regional Development Fund through the Operational Programme for Competitiveness and Internationalisation COMPETE 2020 Programme and by National Funds through the Portuguese funding agency, FCT - Fundação para a Ciência e a Tecnologia within project POCI-01-0145-FEDER-031309 entitled "PromoTourVR - Promoting Tourism Destinations with Multisensory Immersive Media".

\section{REFERENCES}

[1] I. P. Tussyadiah, D. Wang, and C. H. Jia, "Virtual reality and attitudes toward tourism destinations," in Information and Communication Technologies in Tourism 2017, R. Schegg and B. Stangl, Eds. Cham: Springer International Publishing, 2017, pp. 229-239.

[2] A. Sheikh, A. Brown, Z. Watson, and M. Evans, "Directing attention in 360-degree video," 2016.

[3] K. Roose, "360-degree videos are the coolest new thing on youtube," 2015. [Online]. Available: http://fusion.net/story/106108/360-degreevideos-are-the-coolest-new-thing-on-youtube/

[4] R. M. Baños, C. Botella, M. Alcañiz, V. Liaño, B. Guerrero, and B. Rey, "Immersion and emotion: their impact on the sense of presence," Cyberpsychology \& behavior, vol. 7, no. 6, pp. 734-741, 2004.

[5] J. J. Cummings and J. N. Bailenson, "How immersive is enough? a meta-analysis of the effect of immersive technology on user presence," Media Psychology, vol. 19, no. 2, pp. 272-309, 2016.

[6] B. G. Witmer and M. J. Singer, "Measuring presence in virtual environments: A presence questionnaire," Presence, vol. 7, no. 3, pp. 225-240, 1998.

[7] M. Slater and M. Usoh, "Representations systems, perceptual position, and presence in immersive virtual environments," Presence: Teleoperators \& Virtual Environments, vol. 2, no. 3, pp. 221-233, 1993.

[8] A. Correia and C. Moço, "Na senda da satisfao dos turistas. O caso do turismo portugułs," Estudos II, pp. 59-76, 2005.

[9] D.-Y. Kim, X. Y. Lehto, and A. M. Morrison, "Gender differences in online travel information search: Implications for marketing communications on the internet," Tourism management, vol. 28, no. 2, pp. 423-433, 2007.

[10] K. B. Murray, "A test of services marketing theory: consumer information acquisition activities," Journal of marketing, vol. 55, no. 1, pp. 10-25, 1991.

[11] I. A. R. del Bosque, H. San Martín, and J. Collado, "The role of expectations in the consumer satisfaction formation process: Empirical evidence in the travel agency sector," Tourism management, vol. 27, no. 3, pp. 410-419, 2006.

[12] K.-S. Chon, "The role of destination image in tourism: A review and discussion," The tourist review, vol. 45, no. 2, pp. 2-9, 1990.

[13] A. Almeida-Santana and S. Moreno-Gil, "New trends in information search and their influence on destination loyalty: Digital destinations and relationship marketing," Journal of destination marketing \& management, vol. 6, no. 2, pp. 150-161, 2017.

[14] C.-I. Ho, M.-H. Lin, and H.-M. Chen, "Web users behavioural patterns of tourism information search: From online to offline," Tourism Management, vol. 33, no. 6, pp. 1468-1482, 2012.

[15] C. Grönroos, Service management and marketing: Managing the moments of truth in service competition. Jossey-Bass, 1990.

[16] J. E. Bigne, M. I. Sanchez, and J. Sanchez, "Tourism image, evaluation variables and after purchase behaviour: inter-relationship," Tourism management, vol. 22, no. 6, pp. 607-616, 2001.

[17] P. Kotler and D. Gertner, "Country as brand, product, and beyond: A place marketing and brand management perspective," Journal of brand management, vol. 9, no. 4, pp. 249-261, 2002.

[18] W.-B. Chiou, C.-S. Wan, and H.-Y. Lee, "Virtual experience vs. brochures in the advertisement of scenic spots: How cognitive preferences and order effects influence advertising effects on consumers," Tourism Management, vol. 29, no. 1, pp. 146-150, 2008. 
[19] S. Baloglu and K. W. McCleary, "A model of destination image formation," Annals of Tourism Research, vol. 26 , no. 4, pp. 868 - 897, 1999. [Online]. Available: http://www.sciencedirect.com/science/article/pii/S0160738399000304

[20] C. M. Echtner, J. B. Ritchie et al., "The meaning and measurement of destination image," Journal of tourism studies, vol. 2, no. 2, pp. 2-12, 1991.

[21] H. Zhang, Y. Wu, and D. Buhalis, "A model of perceived image, memorable tourism experiences and revisit intention," Journal of destination marketing \& management, vol. 8, pp. 326-336, 2018.

[22] L. Ghisi and S. Macedo, "Turismo virtual on-line: um estudo em sites brasileiros que divulgam o turismo," in III CONVIBRA, Congresso Virtual Brasileiro de Administração, São Paulo, 2006.

[23] I. R. del Bosque and H. San Martín, "Tourist satisfaction a cognitiveaffective model," Annals of tourism research, vol. 35, no. 2, pp. 551-573, 2008.

[24] C. Rafael and A. Almeida, "Impacto da informação online na formação da imagem de destino virtual," Dos Algarves: a multidisciplinary ejournal, no. 23, pp. 27-50, 2017.

[25] O. H. Jenkins, "Understanding and measuring tourist destination images," International journal of tourism research, vol. 1, no. 1, pp. 1-15, 1999.

[26] J. Nadeau, L. Heslop, N. OReilly, and P. Luk, "Destination in a country image context," Annals of tourism Research, vol. 35, no. 1, pp. 84-106, 2008.

[27] C.-F. Chen and D. Tsai, "How destination image and evaluative factors affect behavioral intentions?" Tourism management, vol. 28, no. 4, pp. 1115-1122, 2007.

[28] S. D. F. Lopes et al., "Destination image: Origins, developments and implications," PASOS. Revista de Turismo y Patrimonio Cultural, vol. 9, no. 2, pp. 305-315, 2011.

[29] S. Sönmez and E. Sirakaya, "A distorted destination image? the case of turkey," Journal of travel research, vol. 41, no. 2, pp. 185-196, 2002.

[30] A. G. Woodside and S. Lysonski, "A general model of traveler destination choice," Journal of travel Research, vol. 27, no. 4, pp. 8-14, 1989.

[31] M. J. Sirgy and C. Su, "Destination image, self-congruity, and travel behavior: Toward an integrative model," Journal of Travel Research, vol. 38, no. 4, pp. 340-352, 2000.

[32] A. Phelps, "Holiday destination imagethe problem of assessment: An example developed in menorca," Tourism management, vol. 7, no. 3, pp. 168-180, 1986.

[33] A. Beerli and J. D. Martın, "Tourists characteristics and the perceived image of tourist destinations: a quantitative analysisa case study of lanzarote, spain,” Tourism management, vol. 25, no. 5, pp. 623-636, 2004.

[34] W. C. Gartner, "Image formation process," Journal of travel \& tourism marketing, vol. 2, no. 2-3, pp. 191-216, 1994.

[35] A. D. Tasci and W. C. Gartner, "Destination image and its functional relationships," Journal of travel research, vol. 45, no. 4, pp. 413-425, 2007.

[36] C. Heeter, "Being there: The subjective experience of presence," Presence: Teleoperators \& Virtual Environments, vol. 1, no. 2, pp. 262-271, 1992.

[37] W. A. IJsselsteijn, H. De Ridder, J. Freeman, and S. E. Avons, "Presence: concept, determinants, and measurement," in Human vision and electronic imaging $V$, vol. 3959. International Society for Optics and Photonics, 2000, pp. 520-529.

[38] M. Lombard and T. Ditton, "At the heart of it all: The concept of presence," Journal of computer-mediated communication, vol. 3, no. 2, p. JCMC321, 1997.

[39] E. B. Nash, G. W. Edwards, J. A. Thompson, and W. Barfield, "A review of presence and performance in virtual environments," International Journal of human-computer Interaction, vol. 12, no. 1, pp. 1-41, 2000.

[40] A. Sacau, J. Laarni, and T. Hartmann, "Influence of individual factors on presence," Computers in Human Behavior, vol. 24, no. 5, pp. 22552273, 2008 .

[41] A. Heydarian, J. P. Carneiro, D. Gerber, B. Becerik-Gerber, T. Hayes, and W. Wood, "Immersive virtual environments versus physical built environments: A benchmarking study for building design and user-built environment explorations," Automation in Construction, vol. 54, pp. 116-126, 2015.

[42] S. Kurita, "Presence, involvement, and gender differences: How emotional dimensions explain the mechanism of presence," in annual meet- ing of the International Communication Association, Dresden International Congress Centre, Dresden, Germany Online, 2006.

[43] T. W. M. Day, The Oculus Rift as a portal for presence: The effects of technology advancement and sex differences in the horror video game genre. Michigan State University, 2015.

[44] M. Melo, J. Vasconcelos-Raposo, and M. Bessa, "Presence and cybersickness in immersive content: Effects of content type, exposure time and gender," Computers Graphics, vol. 71, pp. $159-165,2018$. [Online]. Available: http://www.sciencedirect.com/science/article/pii/S0097849317301917

[45] S. P. Ross, R. W. Skelton, and S. C. Mueller, "Gender differences in spatial navigation in virtual space: implications when using virtual environments in instruction and assessment," Virtual Reality, vol. 10, no. 3-4, pp. 175-184, 2006.

[46] I. Sancaktar and H. Demirkan, "Spatial updating of objects after rotational and translational body movements in virtual environments," Computers in Human Behavior, vol. 24, no. 6, pp. 2682-2696, 2008.

[47] J. L. Crompton, "An assessment of the image of mexico as a vacation destination and the influence of geographical location upon that image," Journal of travel research, vol. 17, no. 4, pp. 18-23, 1979.

[48] A. BÄneÈ and A. BogluÈ, "Tourism presentation systems based on virtual reality," Lucrări tiinifice Management Agricol, vol. 15, no. 4, p. 36, 2013

[49] R. Govers, F. M. Go, and K. Kumar, "Promoting tourism destination image," Journal of travel research, vol. 46, no. 1, pp. 15-23, 2007.

[50] C. Sas, G. M. OHare, and R. Reilly, "Presence and task performance: an approach in the light of cognitive style," Cognition, Technology \& Work, vol. 6, no. 1, pp. 53-56, 2004.

[51] T. R. Cutmore, T. J. Hine, K. J. Maberly, N. M. Langford, and G. Hawgood, "Cognitive and gender factors influencing navigation in a virtual environment," International Journal of Human-Computer Studies, vol. 53 , no. 2, pp. 223-249, 2000.

[52] Y. Ling, H. T. Nefs, W.-P. Brinkman, C. Qu, and I. Heynderickx, "The relationship between individual characteristics and experienced presence," Computers in Human Behavior, vol. 29, no. 4, pp. 15191530, 2013.

[53] P. V. Schaik, T. Turnbull, A. V. Wersch, and S. Drummond, "Presence within a mixed reality environment," CyberPsychology \& Behavior, vol. 7, no. 5, pp. 540-552, 2004, pMID: 15667049. [Online]. Available: https://doi.org/10.1089/cpb.2004.7.540

[54] R. L. Oliver, "An investigation of the interrelationship between consumer (dis) satisfaction and complaint reports," ACR North American Advances, 1987.

[55] J. E. B. Alcañiz and L. A. Simó, "Modelo cognitivo-afectivo de la satisfacción en servicios de ocio y turismo," Cuadernos de Economía y Dirección de la Empresa, no. 21, pp. 89-120, 2004.

[56] R. N. Bolton and J. H. Drew, "A longitudinal analysis of the impact of service changes on customer attitudes," Journal of marketing, vol. 55 , no. 1 , pp. 1-9, 1991.

[57] J. M. Carman, "Consumer perceptions of service quality: an assessment of t," Journal of retailing, vol. 66, no. 1, p. 33, 1990.

[58] T. Nemoto and D. Beglar, "Likert-scale questionnaires," in JALT 2013 Conference Proceedings, 2014, pp. 1-8.

[59] D. George, SPSS for windows step by step: A simple study guide and reference, 17.0 update, 10/e. Pearson Education India, 2011. 